\title{
Silent Spring
}

a review by Roy Edwards, Department of Biology, University of Saskatchewan, Saskatoon

SILENT SPRING. By Rachel Carson. 1962. Houghton Mifflin Company, Boston. Price $\$ 5.95$.

This book is a bitter denunciation of the indiscriminate use of chemical pesticides. It does not pretend to be a balanced account of the advantages and disadvantages of chemical control methods but is more in the nature of a case for the prosecution. In spite of this, the author takes care to point out that she is not opposed to the use of pesticides in certain cases. She states her position very clearly on pages 12 and 13. "It is not my' contention that chemical insecticides must never be used. I do contend that we have put poisonous and biologically potent chemicals indiscriminately into the hands of persons largely or wholly ignorant of their potentials for harm. We have subjected enormous numbers of people to contact with these poisons, without their consent and-often without their knowledge . . . I contend, furthermore, that we have allowed these chemicals to be used with little or no advance investigation of their effect cn soil, water, wildlife, and man himself." In two separate places in her book she advocates the use of chemicals for the control of two specific pests-fire ants and woody brush--but in each case she advocates that the chemical be used in small quantities and in a special way.

The book is written in the typical Rachel Carson style-a style that has won her many literary awards but one that is hardly suitable for an attack on a multi-billion dollar industry. It contains a number of emotional outbursts and some frankly misleading statements. For example, in chapter 3 she cites a number of instances where accidental contact with a pesticide was followed within a few hours by the death of the person concerned. The implication is that the chemical caused the death, but only in one instance does she come right out and say so. The danger of jumping to the obvious conclusion in the other cases was shown recently in two separate press reports of farmers who spilled insecticides on themselves and died shortly afterwards. In both cases an autopsy showed that death was caused by a heart attack that was unconnected with the chemical effects of the poison. In Chapters 12 through 14 she tries to link the use of insecticides with the incidence of a number of human ailments including cancer, despite the fact that no positive proof exists.

That she allows her perssonal feelings to intrude so extensively into her book is a pity, because she can make her case perfectly well without them. Her case rests partly on the basis of information acquired incidentally during her sixteen years as a biolcgist in the U.S. Fish and Wildlife Service, but mainly on the results of four years work spent collecting data from all over the world on the effects of pesticides now in general use. She supports her argument with 55 pages of references to scientific papers, books and government reports.

In spite of her emotional outbursts, therefore, her book is not pure sensationalism. If, in parts, it reads something like a horror comic this is because the subject with which it deals is not a pretty one. Nor should the book be considered in the realm

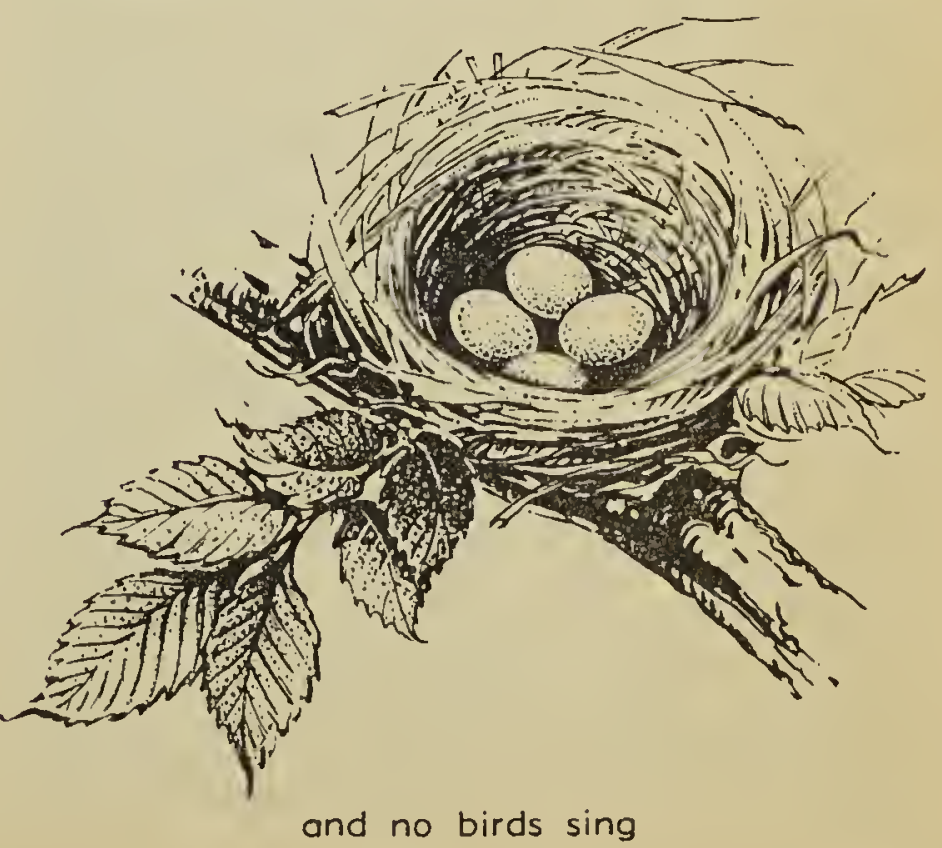


of science fiction; it refers to events that have already happened and her only, projection into the future is in the extent to which these eventssomewhat isolated at present-are likely to become more widespread as the scope of chemical pesticide campaigns increases.

In, the first chapter the author paints an idyllic word picture of an imaginary American town situated in a couner of the land where farms prosper, streams contain abundant fish and the bird life attracts people from, miles around. Then slowly a "strange blight" creeps over the area so that everything begins to change. The vegetation withers, cattle and fish die, families become ill and the birds 'disappear. In the spring, instead bf the usual dawn chorus, there is silence. It is this phenomenonthe silent spring-that gives the book its name. This change in the countryside is: not brought about by enemy action lbut by the people themselves through the indiscriminate use of chemical pesticides.

Although Rachel Carson emphasizes that the town she describes does not exist, nor has any single community ever suffered all the misfortunes she describes, "yet every one of these disasters has actually happened somewhere and many real communities have already suffered a substantial number of them." The remaining chapters of the book deal in greater detail with the various aspects cf this "strange blight." The facts that she has to report make spine-tingling reading.

In Chapter 2 she points out that very few species of plants and animals are really serious pests and that man himself is largely responsible for those that are. The transportation of plants and animals from one continent to another where they are free from their natural enemies allows them to multiply unchecked. In addition to this the intensification of agriculture which concentrates a pest's most suitable habitat sets the stage for an explosive increase in its numbers. The attempts to control these pests with the aid of chemicals has led to a tremendous increase in the numbers of pesticides developed in recent years. Since the mid-1940's some 200 basic chemicals have been created for use against pests of one sort or another. Where these are sprayed indiscriminately over the countryside "good" organisms are killed as well as "bad."

In Chapter 3 the chemistry of a number of poisonous chemicals used in pest control is described briefly together with the way in which they affect living organisms. She points out that the quantities that are left as a deposit on plants or are found in the tissues of animals are expressed in terms of parts per million ( $\mathrm{ppm}$ ) and although these quantities may be exceedingly small they may have a very marked effect on a living animal. In experimental animals $3 \mathrm{ppm}$ of D.D.T. have been found to affect an enzyme present in heart muscle and $5 \mathrm{ppm}$ have brought about disintegration of the liver cells.

Rachel Carson draws attention to the existence of food chains in the animal world-how animals that feed on plants are themselves eaten by other animals which in turn may be eaten by still larger ones. She brings out the point that in this way poisonous chemicals deposited on the initial plant food are passed from one animal to another in the food chain and-most important of allthat when these substances are persistent poisons such as D.D.T. and its related compounds, the concentration increases at each level. For example, when alfalfa is dusted with D.D.T. the hay may contain 7 or 8 parts per million as a residue. But when this hay is fed to cows it may appear in the butter fat at 65 parts per million.

The way these quantities can builc up in long food chains is quite dramatic. In an attempt to control gnats at Clear Lake, California, the water was treated with D.D.D. Three applications were made over a period of eight years and the dosage rate was one fiftieth of a part per million. Although no trace of the chemical could be found in the water "shortly after" the last application, it still persisted at the rate of $5.3 \mathrm{ppm}$ in the microscopic organisms of the lake some two years later. After 12 months, all fish, frogs and birds that were examined showed the presence of D.D.D. in their tissues; gulls, which had fed on the fish, contained as much as 2,000 ppm. Meanwhile the population of western grebes on the 
lake has dropped from 1000 pairs in 1948 to 30 pairs in 1960. Moreover no young grebes have been found on the lakes since the last application of D.D.D. in 1957.

This absence of offspring is a typical effect of sub-lethal doses of insecticides. Birds that have been exposed to insecticides but have not received a fatal dose have shown greatly reduced fertility and in several cases complete sterility. One of the most dramatic cases occurred on the campus of Michigan State University. In a normal year there would be some 370 adult robins on the 185acre campus and in late spring about the same number of young birds. In 1954, in an attempt to control the insect responsible for the spread of Dutch elm disease, the campus was sprayed wtih D.D.T. The insecticide was deposited on the elm leaves, carried into the soil in the fall where it was stored in the bodies of earthworms that eat the leaves. In the spring the earthworms were eaten by the robins which in many cases died as a result but in other cases became sterile. Analyses showed that ten males had amounts of D.D.T. ranging from 30 to $109 \mathrm{ppm}$ in the testes while two females had 151 and $211 \mathrm{ppm}$ in the ovaries. The effect of this on the robin population was obvious; in 1957 only one young robin was found and in 1958 not a single fledgling was seen anywnere on the campus.

The persistence of poisonous chemicals in the soil is dealt with at some length. Aldrin has been recovered from soil after 4 years, toxaphene after 10 years, benzene hexachloride after 11 years, heptachlor after 9 years, and chlordane after 12 years at $15 \%$ of the original quantity. The combined effect of persistence and repeated treatment give incredibly high concentrations in certain circumstances. Corn soils have been found to contain $19 \mathrm{lbs}$. of D.D.T. per acre, a cranberry bog had 34.5 lbs. per acre, and under trees in an apple orchard the concentration reached 113 lbs. per acre.

These high concentrations of chemicals in the soil can affect crops for years after treatment has ceased. The amount of arsenic present in cigarettes made from American tobaccos increased $300 \%$ between 1932 and 1952 and later studies (date not given) shows a continued increase to $600 \%$. This has occurred in spite of the fact that arsenic poisons were largely replaced by organic insesticides in the mid-1940's.

In some sensitive plants-such as beans, wheat, barley and rye-root development is retarded by insecticides. Hop growers in Washington and Idaho treated their vines with heptachlor to control root weevil. Within a year the vines had withered and died. Although the fields were replanted the new piants als o died. The U.S. Department of Agriculture which had declared heptachlor acceptable for use on hop vines hurriedly withdrew its registration of the chemical for such use. However, they could offer no solution to the problem of how to overcome the contaminaticn of the soil nor (after four years) could they give any indication of how many more years the soil would remain poisonous.

The extent to which we are exposed to insecticides in our daily lives is quite surprising. Insecticides are used to moth-proof clothes; kitchen shelf paper may be impregnated with insecticides to kill flies; floor polishes and waxes may contain insecticides; gardens and lawns can be treated by insecticides in jars attached to the garden hose, and so on. Especially is our food supply liable to be contaminated. When the United States Public Health Service tested meals served in restaurants and institutions they found that every meal they sampled contained D.D.T. In some cases, the amounts were very high; in stewed dried fruit it reached $69.6 \mathrm{ppm}$ and in bread it reached $100.9 \mathrm{ppm}$. When tests were made of the foods eaten by Eskimos on the Arctic shores of Alaska it was found that they were all free cf D.D.T. However, a small proportion of the Eskimcs themselves had small residues of D.D.T. in their tissues. These had been to the U.S. Public Health Service at Anchorage for surgery and had there eaten normal, civilized, contaminated food!

The mixing of two separate insecticides in the mammalian system can be particularly dangerous. Malathion on its own is relatively harmless because the mammalian liver produces an enzyme that detoxifies it. But if another insecticide that attacks the liver enzyme is also present, the body 
receives the full effect of malathion poisoning in addition to poisoning by the other insecticide. In such cases as little as one hundredth part of what is normally considered to be a "safe dose" may prove to be fatal. The common salad bowl containing a variety of different vegetablesand hence different insecticides-can be a common source of danger in this respect.

Rachel Carson is particularly scathing in her attacks on State and Federal Departments of Agriculture. She describes their efforts to control the fire ant in the southern U.S. as "an outstanding example of an ill conceived, badly executed, and thoroughly detrimental experiment in the mass control of insects." Although the fire ant has been present in the area for 40 years and there had been no report of damage to either crcps or animals during the previous 5 years, the U.S. Department of Agriculture declared in 1957 that it constituted a serious threat to southern agriculture and called for a large scale chemical control campaign. In the first year an area of one million acres was sprayed from the air with heptachlor and dieldrin. Studies by biologists in State and Federal Wildlife Service, and in the universities, reported complete destruction of wildlife in some areas, together with severe losses of pigs, chickens, turkeys and livestock, and the appearance of heavy concentrations of heptachlor and dieldrin in their tissues. After 4 years of control work the director of Entomological Research at Louisiana State University described the programme as a failure because more areas were infested with fire ants than ever before, while in Florida the program was abandoned because "there are more fire ants in Florida now than there were when the program started." In the meantime, an accounting of the costs showed that whereas the mass control program had cost $\$ 3.50$ per acre and had failed, the Mississippi Agricultural Experiment Station had been achieving 90-95\% control at a cost of $\$ 0.23$ per acre by using the cultivator and local poisoning methods.

In chapter 15 which bears the title "Nature fights back" Rachel Carson says "To have risked so much in our efforts to mold nature to our satis- faction and yet to have failed in achieving our goal.would indeed be the final irony. Yet this, it seems, is our situation." There follows a series of examples of insecticide campaigns which appeared to succeed at first, but then left the situation worse than it was before. For example, blackflies in Ontario became 17 times as abundant after spraying with chemicals as they were before; an unparalleled outbreak of cabbage aphids occurred in England following the application of an organic phosphorus chemical; there was a sharp outbreak of spider mites when trees in the Western U.S. were sprayed with D.D.T. in an attempt to control spruce budworm. In Nova Scotia in the late 1940's the worst infestations of codling moth occurred in orchards that were regularly sprayed, while in unsprayed orchards the moths were not abundant enough to cause real trouble. The siheme of reduced spraying that is now practised in Nova Scotia apple orchards under the guidance of Dr. A. D. Pickett comes in for particular praise as " a sane method of insect control that takes full advantage of predatory and parasitic species. The method which he and his associates evolved is today a shining model but one too little emulated."

Chapter 16 sounds a warning regarding the development of resistant strains of insect pests. When a pest population is sprayed with an insecticide not all the individuals are killed. Some have greater resistance than others and can survive. These give rise to offspring that also have increased resistance so that a heavier dose of chemical is required to kill them. Some of these are again more resistant and survive the heavier dose so that after a number of generations the insect pests can actually be fed large doses of the same chemical that was originally used to control them. This is no dream, it is happening all the time, and is happening very quickly. In 1956 only 5 species of mosquitoes showed resistance to D.D.T. but by 1960 the number had increased to 28 and in the same year the number of known resistant species among crop-destroying insects had reached 65 .

In her final chapter Rachel Carson suggests "the other road." This is the use of biological methods for the 
control of pests. She cites a number of spectacularly successful biological control schemes that have been carried out. For example, the control of cactus in Australia by an imported moth and the control of the screw worm in Curacao by releasing vast numbers of irradiated males which, being sterile, were unable to reproduce, so that the population eventually died out. She cites a number of other cases where success in controlling a pest insect has been achieved by the use of natural enemies, parasites and diseases. The cost cf running these biological control schemes is negligible once the key to the problem has been found, but it requires a tremendous amount of diligent research, a lively imagination and, of course, adequate financial support in the early stages to uncover the necessary clues. Biological control programmes are unglamorous in their early stages as they can seldom produce the spertacular initial results that a chemical spray programme can. Moreover, when a biological control programme is running properly the insects themselves do the work and there is no opportunity for an industrial concern to make any profit. It is not therefore a field to which industrial enterprises would be attracted. In spite of the heavy cost of the initial outlay biological control methods can effect quite spestacular savings in the long run. In California, where biological control methods have been practised for many years it has been estimated that for an investment of $\$ 4,000,000$ in biological contrcl work the State has received a return of $\$ 100,000,000$ and the savings continue at the rate of millions of ällars annually.

Rachel Carson points out that the rapid expansion of chemical control campaigns and the lack of awareness of the nature of the threat has come aiout because the majority of entomolcgists are working in the field of economic entomology where their research work is supported by the insecticide firms themselves. Government Departments of Agriculture have aided this trend by pouring millions cf dollars into insecticide campaigns c.ften without any more than a cursory examination of the situation with which they are dealing. At the same time there has been an acute shortage of funds for research into other branches of pest control where quick results could not be promised. Moreover, when evidence has been obtained of the inadequacy of the insecticidal campaigns and of the unpleasant side effect asscciated with their use, the fears of the public have been allayed either by suppressing the information or by discrediting the findings of the

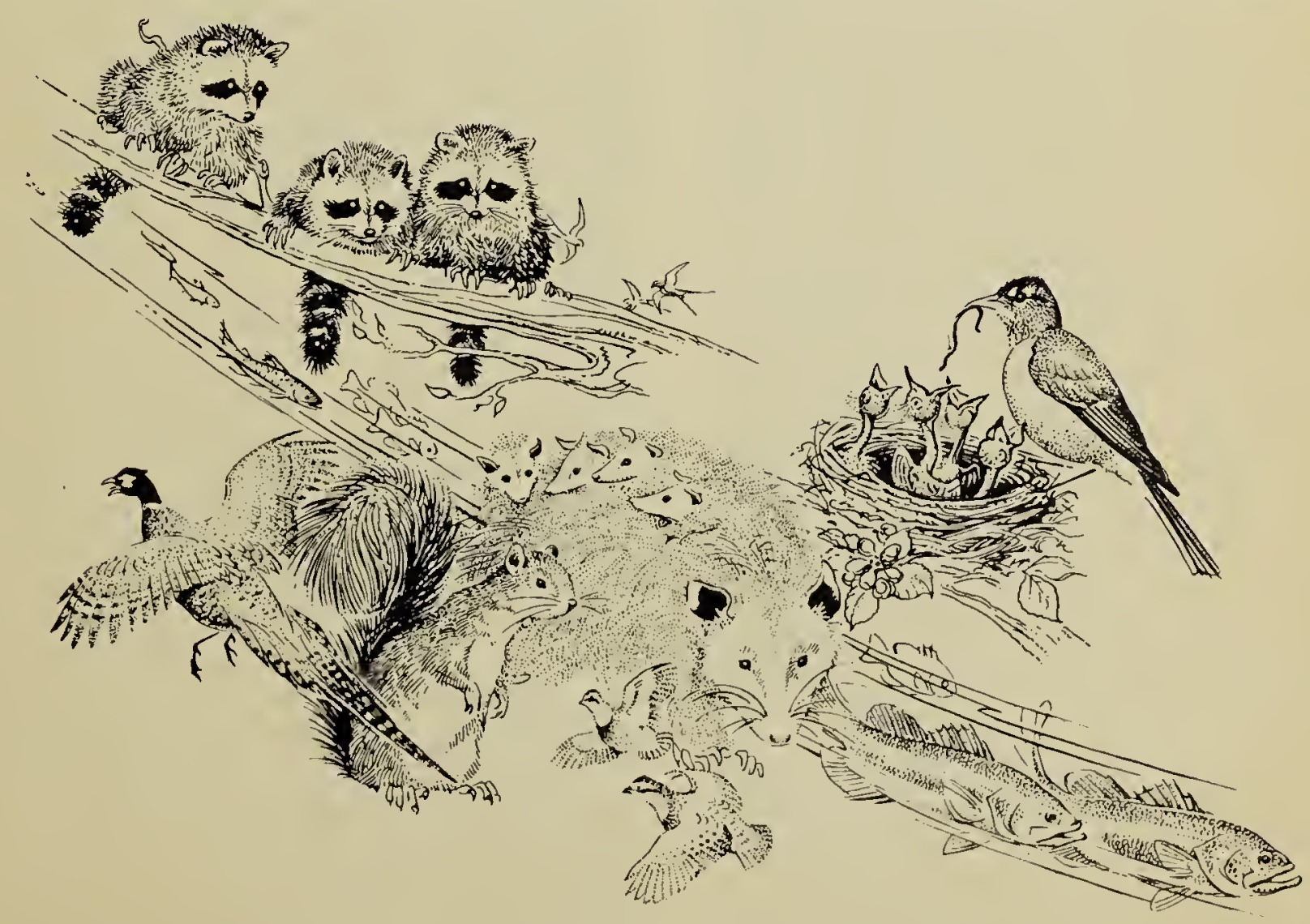

Illustration from page 84 Silent Spring by Rachel Carson. 
investigator. "This is an era of specialists, each of whom sees his own problem and is unaware of or intolerant of the larger frame into which he fits. It is also an era dominated by industry, in which the right to make a dollar at whatever cost is seldom challenged. When the public protests, confronted with some obvious evidence of damaging results of pesticide applications, it is fed little tranquilizing pills of half truth. We urgently need to end these false assurances, to the sugar coating of unpalatable facts."

This, then is the theme of the book "Silent spring." It can be stated briefly as condemning the indiscriminate use of chemical insecticides on three counts-1. They are undesirable because of the dangers to animals including human beings, 2. they are unsuccessful because, among other factors, the pest species develops resistant strains, and 3. they are unnecessary because other means of control-biological control-is available to us if we are on'ly prepared to spend the time and money to look for it. To these three she adds the fourth point-the deliberate suppression of information by those associated with chemical control work.

Is her case sound? In the opinion of this reviewer it is. Her unfortunate decision to include in her book much that is open to question will be picked upon by the opposition as a weapon with which to condemn it. But the undeniable fact remains that much of which she says is true and proven beyond doubt. Her case should not be considered unsound because she throws in some unreliable evidence in addition. She produces definite proof that in a large number of instances chemical insecticides have proved dangerous and even fatal to animals and in some cases to human beings; she has shown instances of the failure of expensive chemical control campaigns, and she has shown that in a few instances biological control of a pest can be dramatically successful.

That this book will be the centre of a great deal of controversy goes without saying. The chemical control of pests is a major industry in which thousands of people, from manufacturers and salesmen to economic en- tomologists and local spray operators, depend for their livelihood. We are never more sensitive about any topic than when it threatens our source of income and opposition from the insecticide industry will be considerable. There will also be strong opposition from government Departments of Agriculture who have plunged deeply into chemical control programmes and have been treated roughly by Rachel Carson for doing so. At present, support for the book will come from those who are concerned with the protection of wildlife, from those entomologists who have been concerned for a long time about the possible consequences of the indiscriminate use of chemicals for the control oti insects, and from those few members of the public who have been fortunate enough to have firsthand experience of those consequences. The bulk of the population will see no reason why they should be concerned over a controversy that seems to be on a rather technical plane and with which they are apparently not too closely concerned. However, as time goes by and the insecticide firms put into effect their avowed intention of extending the scope of their pesticide programmes, more and more people will find that they can no longer ignore this threat to their well-being and their attitude then will be interesting to watch.

The real crux of the matter of course lies in the frequency with which these phenomena occur. What is the percentage of the whole population that can expect to suffer detrimental effects through accidental contamination 'with insecticides? On reading the book, one almost feels the symptoms of insecticide poisoning coming on before reaching the last page. The fact is of course that far fewer people are killed by insecticides than are killed by automobiles. Should we then drastically curtail the use of automobiles? Obviiously not, because their value to our society far outweighs their lethal potential. As with automobiles so with pesticides. We must take a balanced view of the whole situation. We must balance the possibility of crop losses against the dangers of contaminating the crop, the soil, and the water supply; we must balance the opportunity for profits-and employment-in the insecticide indus- 
try against the importance of wildlife, not only as a sport and as a tourist attraction, but also for its own sake; above all, we must weigh the opportunity for short-term gain against the possibility of long-term loss. There is no point whatsoever in striving to get the last bushel of crop from our land this year if in so doing we render our produce unmarketable through an excess of insecticide residue or make the soil unsuitable for food production in the future. Under these circumstances it might be better to treat the loss of a small percentage of crop as a "kind of insurance premium that we pay to the insects to insure the continued marketability of our produce.

Most of what is said in the book refers to events that have occurred in the United States. How are we in Saskatchewan affected by it? We are a grain producing country where in our efforts to control grasshoppers, wireworms and cutworms we have poured thousands of pounds of chemical insecticides on the land every year for many years past. There appears to be no information as to whether we are contaminating our own food, but the fact that many of our fruits and vegetables come trom the United States where residues have been detected in considerable quantities makes' it almost certain that we, too, are eating contaminated foods. Is there any evidence of insecticide resistance in our native pest insects? None has been found ibut apparently none has ever been sought. It is significant that in Ontario recent tests have shown that cutworms are "highly tolerant" to dieldrin, D.D.T. and Diazinon. Is there any evidence of damage to crops? None whatsoever. Even if grain yields over the past 60 years have not shown the dramatic increases that have occurred in other crops, at least the yields have not dropped very much, and one can always argue that if insecticides had not been used the crop yields might have been much lower. Nevertheless, there appears to be little diminution of grasshopper outbreaks in spite of the heavy expenditure on insecticides. It was officially predicted that 1962 might provide us with one of the worst outbreaks in Saskatchewan's history. Admittedly this is only one year in many and it is not anticipated that 1963 will be quite as bad but one might have hoped to see a considerable drop in numbers. Once again, it can always be argued that if insecticides had not been used the situation would have been far worse; and as long as no properly controlled experiments are undertaken to test this possibility, the matter remains in doubt. But it is also certain that no one has ever shown that crop yields in this province have been increased by the use of insecticides and in view of the possibility of deleterious side effects one might at least question whether the expense of a large scale insecticide campaign is justified. Is there any possibility that biological control methods could be used against grasshoppers? Some preliminary work was stanted a few years ago but none is being done at the present time. Is there any evidence that the use of insecticides has had any deleterious effect on the wildlife of Saskatchewan? There appears to be no evidence that it has. The gradual decline in the duck population over the past 6 years can be explained perfectly logically by the increasing drought conditions that have occurred. There is no reason at all to link it with the increased use of dieldrin that began in 1956, though of course lack of evidence of a relationship cannot be taken as proof that such a relationship does not exist. Ducks taken from hunters bags in Colorado have shown the presence of dieldrin in amounts to $30 \mathrm{ppm}$ but no tests appear ito have been made on ducks shot in Saskatchewan.

In summary, then, we in Saskatchewan either have no problem with insecticides, or if we have, we are unaware of it. However, the possibility that we shall have one in a few years time is very real. If we do nothing else, we should at least begin to look very carefully at the situation in this Province and try to find out just what effect insecticides are having, not only on the pests against which they are being used and on the crops that they are supposed to protect but also on our wildlife and on ourselves. Alternatively, we can ignore Rachel Carson's warning, we can overlook the noisy arguments that will be fought out south of the border and we can enjoy the peace and quiet of our countryside-in silent Saskatchewan. 